\title{
A Study on the Talent Training Model Based on the Combination of Supply-Side Structural Reform and Engineering Certification
}

\author{
Jie Dong ${ }^{1, a^{*}}$ and Jingke $\mathrm{Xu}^{1, \mathrm{~b}}$ \\ ${ }^{1}$ Shenyang Jianzhu University. No.9, Hunnan East Road, Hunnan New District, Shenyang \\ City, Liaoning, P.R.China \\ a623236930@qq.com, b1401308379@qq.com
}

Keywords: Higher education; Supply-side reform; Engineering certification; Training model

\begin{abstract}
The training of excellent talents is the main goal of higher education, but there are some problems, such as contradiction between demand and supply, imbalance of resource distribution, low efficiency of supply, etc. The supply-side reform of higher education and the certification of international engineering education are the inevitable trend of the development of engineering majors in various universities of our country from different views, which could improve the quality of all students' training, to promote the structural optimization and adjustment of higher education, to expand the effectiveness of supply, and to promote the healthy and effective development of higher education. Based on the above dual perspective, the paper puts forward the re-design of the training goal of professional talents under the concept of outcome-oriented and output-oriented and the positive implementation of student-centered training, and discusses the teaching methods, the establishment of quantitative evaluation system and the continuous improvement system. It will be a new way to promote the deep and sustainable development of engineering specialty in China.
\end{abstract}

\section{Research Background}

Quality is the eternal theme of higher education. Engineering education certification is an internationally accepted quality assurance system for engineering education. The core is a training goal and graduation export requirements as the orientation of eligibility evaluation, which confirms that engineering graduates meet the established quality standards approved by the industry. The supply-side reform, starting from improving supply quality, optimizes the supply structure by means of reform, corrects the distorted status quo of resource allocation, reduces inefficient supply at the low end, and expands the effective supply at the middle and high end, strengthens the flexibility of supply mode, improve the efficiency of supply, so as to meet well the needs of society, and realize the sustained and coordinated development of all aspects of society. In the process of supply of higher education, there are also some problems, such as imbalance of supply structure and "one side" of the main body of supply. The supply-side reform has a positive effect on the adjustment of supply and demand structure in higher education. The Department of Education of Liaoning Province has put forward the "opinions of the Liaoning Provincial people's Government on the implementation of the supply-side structural reform of senior high schools and other schools." although the two views are different; they have greatly promoted the transformation of undergraduate universities and colleges into application-oriented ones. It is necessary to optimize the structure of discipline and specialty, strengthen the adaptability of supply and demand for talent training, and adjust the supply structure. Therefore, under the new situation, it is necessary to probe into the new teaching mode of higher education in our country and improve the quality of education in our country.

\section{The Basic Theory of Higher Education Supply-Side Reform and International Engineering Specialty Certification}

Implications of Supply-Side Reform in Higher Education. It is one of the main goals of higher education supply to transport outstanding talents to market in order to promote the progress of the country. The supply of higher education has two main meanings: one is the opportunity for all kinds of universities to supply higher education for each individual in need; the other is directed towards the 
introduction of excellent, diversified and highly qualified personnel with professional qualities into the society, which ensure the normal needs of the sustainable development of all aspects of society. The two are inextricably linked[1].

After providing students with educational opportunities, they are trained to meet the needs of various fields of the market. As the main bearer of higher education supply, university acts as a bridge between individual and society.

Basic Concepts of International Engineering Professional Certification. In the stage of popularization of higher education, the basic concept of international engineering professional certification has paid more attention to the quality of education than ever before in China. Higher engineering education is an important part of higher education in China. With the expansion of engineering education scale, the state has put forward higher quality requirements for engineering education. Engineering education professional certification is an important means to construct engineering education quality guarantee system, which promote the reform of engineering education, to improve engineering education level, and aim at the continuously improving the quality of engineering education. In engineering certification, there are three main concepts: "student-centered", "production-oriented" and "continuous improvement of quality".

By carefully studying the standards of engineering certification at home and abroad, we can find that the basic knowledge, ability and quality of the graduates must be clearly defined, which embodies the tenet of "taking students as the center and serving students". So that the students can meet the needs of the society and the university education is another important index of the domestic engineering certification, so the "student" is listed as the primary factor.

Engineering certification does not stipulate a fixed pattern, but advocates that colleges and universities should develop their own specialties on the basis of meeting the basic requirements. Universities and colleges could give full play to their own advantages and independently determine the direction of development after they have reached the basic requirements in various professional fields,

The engineering education professional certification of engineering education requires the establishment of professional curriculum system, teaching staff and the allocation of school conditions, all of which revolve around the core task of achieving the graduation ability of students. It also emphasizes the establishment of professional continuous improvement mechanism and culture to ensure the quality of professional education and the vitality of professional education.

The system of engineering certification has altered the way of paying attention to the input of educational resources in the past, paying special attention to the output of students, and describing it in a clear and detailed way, evaluating the students in a quantitative way of examining and obtaining evidence. According to the input of various kinds of educational resources in colleges and universities, the use and its process are investigated, and finally the educational output is obtained. This kind of result-based education has brought about a new educational model: the Outcome Based Education (OBE).

At present, the evaluation of teaching quality in colleges and universities has promoted the improvement of educational quality in different degrees, but there are still some deficiencies in the continuous improvement of educational quality. Engineering certification has been strengthened in this respect. For each certified specialty, a certain period of validity is set. After reaching the validity period, colleges and universities need to apply again to extend the validity period, and the engineering certification committee will re-examine these colleges and universities after receiving the application. Only after evaluation can the validity period be extended uniformly, this ensures continuous improvement in the quality of education, rather than short-term measures for certification.

\section{The Construction of Cultivation System under the New Situation}

There are some problems in the development of higher education supply in China, such as the contradiction between demand and supply, the imbalance of resource distribution, the low efficiency of supply and so on, which need to be solved in the process of optimizing the structure of higher education. Based on the supply-side structural reform, taking engineering education professional 
certification standard as the premise, drawing lessons from the advanced development experience at home and abroad, taking the training quality of all students as the center, and according to the characteristics of the school and specialty, it is reasonable to position, Adjust the supply structure of higher education and promote the overall, individualized and maximized growth of all college students.

The Process of Redesigning the Training Program. Based on the market demand, corresponding to the basic requirements of the major training program, and using for reference on the experience of the similar majors at home and abroad from the perspective of the development of international higher education[2], this paper analyzes and studies the problems existing in the current professional curriculum system and the future development trend. Guided by the market demand and the students' graduation requirements, the author makes a training plan with professional characteristics and meets the needs of the times. The overall work plan shown in figure 1 as follows.

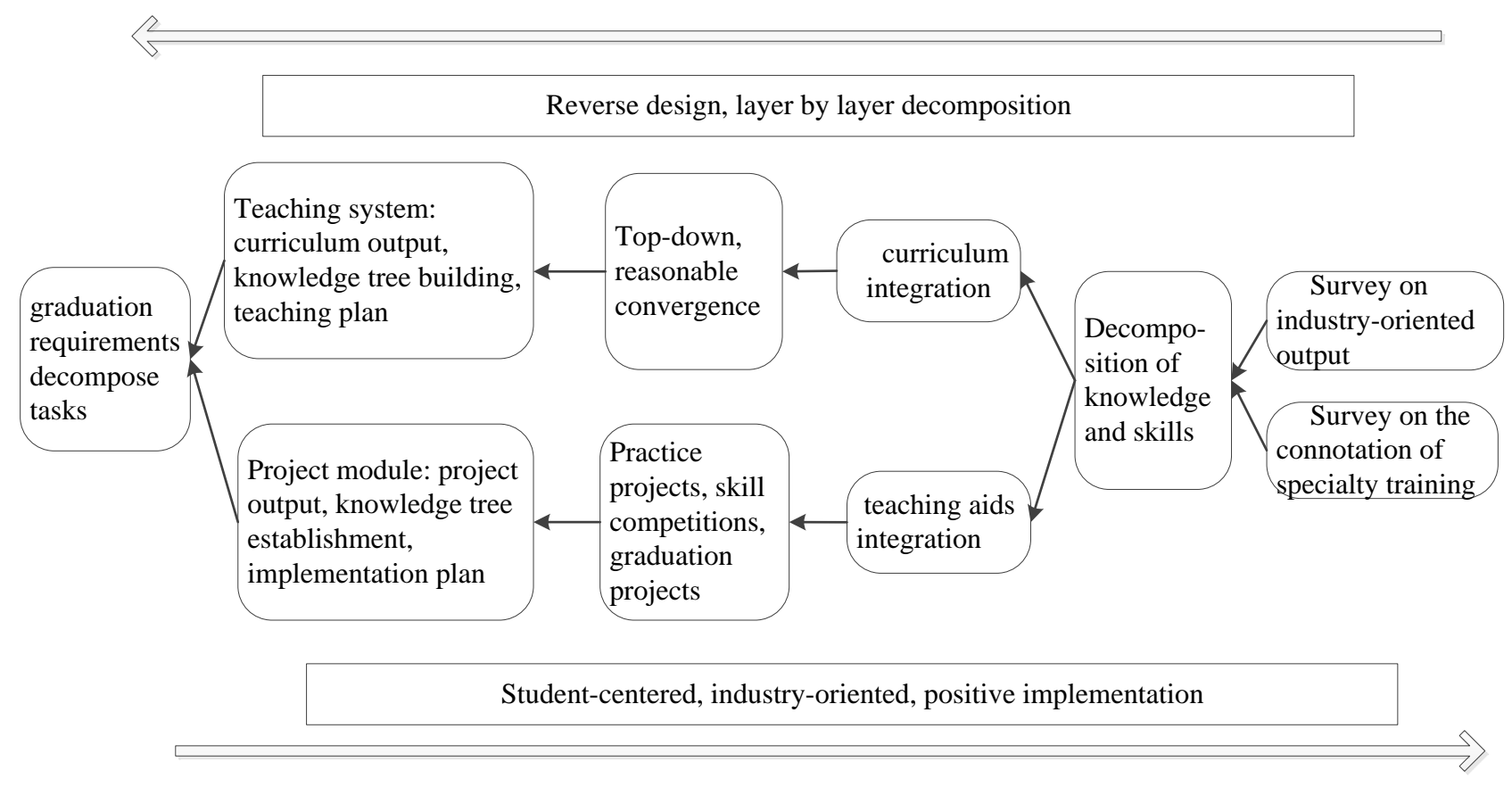

Fig. 1 Overall reform program

In Fig. 1, professional output research can be conducted by means of questionnaires, visits and symposiums, and so on. Enterprise-oriented research are surveyed from multiple angles through top-down survey methods, such as visiting business leaders, investigating personnel departments and relevant production and development departments, holding expert interviews, investigating successful cases in other colleges and universities, following up and returning the employment of graduates, we should investigate the technical application of their major, the educational background of existing technical talents in enterprises, and the source of talents, the relevant knowledge and skills needed for function and practice.

The goal of teaching design and implementation is the result of students' study, so the whole reform plan should adopt the method of reverse design and decompose layer by layer, that is, we carry on the enterprise research, investigate the students' specific needs in the specialty skill, at the same time, according to the graduation requirements of the goal design, the related ability and knowledge structure are dismantled and reconstructed, the curriculum outline and course year content are redesigned, and the experience of other universities is also used for reference, we cultivate students' comprehensive, practical and innovative ability to solve complex engineering problems. In the implementation of the teaching, the positive teaching process is student-centered, which should meet the training requirements through the process learning. At the same time, we should improve the evaluation mechanism to ensure the continuous improvement of teaching. 
The clear teaching goal required by engineering certification is the starting point and destination of teaching,that is the basis of teaching content, teaching method and teaching evaluation means. Such a design process helps to plan the measurable learning goals clearly, which are the cornerstone of engineering certification.

Teaching Method. Based on the dual conditions of supply relationship and engineering certification, teachers should change their ideas and set up teaching service concept-"Education is service, students are customers". Before teaching, students should have a clear understanding of the professional level, and the teachers should carry out various teaching activities under the detailed syllabus, and choose teaching methods consistent with the training objectives. In the past, the teachers of various specialties decided on their own teaching content personally with few constraints[2]. This kind of individual-based random teaching should turn to standard team-based teaching. In order to achieve the goal of professional training, all kinds of courses, Experiment and other types of educational resources, and each teacher's teaching activities should mix up as the organic integration. For the professional common goal, effective convergence and coordinated measures could avoid low-level teaching behavior. In order to avoid the waste of teaching resources, teachers should constantly check and summarize the students' learning effect, reflect on the teaching design, the rationality and effectiveness of teaching activities, carry out the continuous modification of teaching work. At the same time, the change of teaching methods will lead to the supervision, control and evaluation of the teaching process by the teaching supervision department, which increase the teaching workload, so the teachers should be guided correctly.

Establishment of Quantitative Evaluation System and Continuous Improvement System. With the development of society, the talents cultivated in colleges and universities must adapt to the changing needs of the society. The functions of establishing evaluation system are to find out the problems in teaching process and improve them in time instead of the fixed time or stage only, which include an external evaluation system (employers, co-construction enterprises) and an internal evaluation system.

At present, the standard measured the success of college teaching is still the final examination results. On the one hand, the structure of the examination papers is not bulit in detail, and it is not clear that the students can really meet the graduation requirements. This evaluation is rather vague. The reason is the lack of hierarchical quantitative way, but there is no corresponding mechanism to monitor the next exam paper, and the teaching method can not be improved on the corresponding knowledge points, and the improvement of evaluation feedback is weak, although there is an analysis process in the test paper, there is no corresponding mechanism to monitor and control the next. The teaching effect is difficult to improve continuously.

In order to ensure the implementation of the core idea of continuous improvement of the teaching effect of engineering certification, the closed-loop should be formed in six links, such as the course requirements, teaching methods, teaching content, evaluation system and continuous improvement. Teachers and teaching management departments in colleges and universities should study the problems in evaluation to form a good cycle of "implementing teaching \& evaluating \& reflecting \& improving", as shown in figure 2. In order to achieve archival management, we should record each teaching implementation, evaluation results, improvement measures and programs, and track the results of improvement according to a certain period of vertical comparison. The feedback mechanism may promote and improve the quality of professional training.

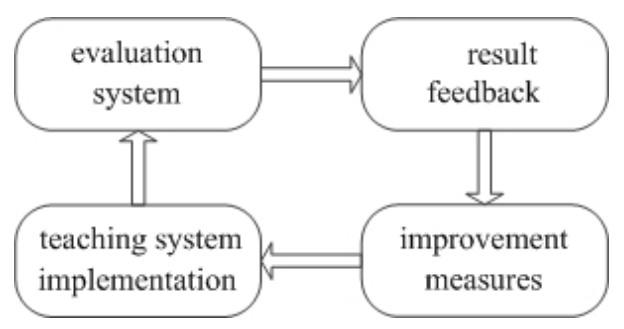

Fig. 2 Continuous improvement of teaching model 


\section{Conclusion}

Under the new normal state of economy, new changes have appeared in the economic structure of our country, and new demands have been put forward for talents of different levels. Engineering certification has brought new ideas and new topics to the teaching of colleges and universities where the main talents are transported, and the reform of education and teaching must keep pace with the times. Through the new concept of supply-side structural reform and engineering certification, the reform of talent training mode, the reconstruction of teaching system and evaluation mechanism, the quality of education can be improved and sustained development, and the effective supply of professional talents can be improved.

\section{Acknowledgements}

This thesis is funded by the training program of undergraduate talents of Shenyang Jianzhu University.

\section{References}

[1] P.P. Xu: Research on supply-side reform of higher education, Liaoning (MS., Shenyang Normal University, China,2017),p.3. (In Chinese)

[2] N.C. Yao, M. Xu: Vocational Education Communication. (2018)No.2, p.10. (In Chinese)

[3] W.L. Hu: Research on Higher Engineering Education. (2015) No.2, p.73. (In Chinese) 